\title{
Use of group-specific PCR primers for identification of chrysophytes by denaturing gradient gel electrophoresis
}

\author{
Johnny Berglund ${ }^{1,2, *}$, Klaus Jürgens ${ }^{3,4}$, Iris Bruchmüller ${ }^{3}$, Mats Wedin ${ }^{1}$, \\ Agneta Andersson ${ }^{1,2}$ \\ ${ }^{1}$ Department of Ecology and Environmental Science, Umeå University, 90187 Umeå, Sweden \\ ${ }^{2}$ Umeå Marine Science Centre, 91020 Hörnefors, Sweden \\ ${ }^{3}$ Max Planck Institute for Limnology, Department of Physiological Ecology, PO Box 165, 24302 Plön, Germany \\ ${ }^{4}$ Baltic Sea Research Institute Warnemünde, 18119 Rostock, Germany
}

\begin{abstract}
The chrysophytes Chrysophyceae and Synurophyceae are ecologically important groups of autotrophic, mixotrophic and heterotrophic flagellates. The smallest forms are difficult to identify by classical microscopy but have important functions both as primary producers and as consumers of bacteria in the aquatic food chain. Group-specific primers for amplification of the $18 \mathrm{~S}$ small sub-unit rRNA gene were developed for analysis of chrysophyte diversity by denaturing gradient gel electrophoresis (DGGE). Two different primer pairs were tested. The first primer pair (EukC1F-Chryso-R) primarily targeted Paraphysomonadaceae and Ochromonadales, which generally have heterotrophic or mixotrophic nutrition. The second primer pair (EukC2-F-Chryso-R) targeted both Chrysophyceae and Synurophyceae. The primer pairs were tested for PCR amplification of the $18 \mathrm{~S}$ rRNA gene of 25 cultured chrysophyte species and 6 other closely related nanoplanktonic species. Both primer pairs performed well, since PCR products were obtained for the corresponding chrysophyte cultures. None of the non-chrysophyte species were amplified with these primers. PCR products of chrysophyte cultures could be separated by DGGE in a denaturing gradient from 40 to $60 \%$. In order to test this PCR-DGGE system for natural planktonic systems, we used field samples from a brackish water area (Baltic Sea) and a freshwater lake. The most intense DGGE bands were excised, sequenced and compared to sequences in GenBank. All obtained sequences grouped within the chrysophytes. Thus, the method seems to be promising for examining chrysophyte diversity in planktonic systems.
\end{abstract}

KEY WORDS: Chrysophytes $\cdot$ Chrysophyceae $\cdot$ Synurophyceae $\cdot$ Heterotrophic nanoflagellates · Denaturing gradient gel electrophoresis $\cdot$ DGGE $\cdot$ PCR-primers $\cdot 18 \mathrm{~S}$ ribosomal DNA

\section{INTRODUCTION}

Nanoprotists (photosynthetic and heterotrophic flagellates within the size range 2 to $20 \mu \mathrm{m}$ ) are important in marine and freshwater systems as primary producers, as consumers of picoplankton and as remineralisers of nutrients (Sherr \& Sherr 2002). Despite their importance, our knowledge about their diversity, autecology and biogeography is poor. Although they can in principle be identified by conventional light and electron microscopy, their identification is time con- suming, can often only be done by experts and, for some groups, is limited to the genus level due to the lack of diagnostic morphological features (e.g. scales). The smallest naked, heterotrophic and mixotrophic flagellates are particularly difficult to distinguish and many forms remain unidentified after microscopy studies (Arndt et al. 2000).

During the last decade, molecular methods have been developed to study the diversity of indigenous microbial communities independently of classical techniques requiring cultivation and microscopic identifi- 
cation (e.g. Amann et al. 1995, Schäfer \& Muyzer 2001). The methods, which are mostly based on the analysis of the small-subunit (16S or 18S) ribosomal RNA gene, have provided new possibilities for ecologists to examine microbial diversity and to identify the major players within microbial food webs. Although most of these molecular studies focused on prokaryotes, similar methods can be applied to eukaryotic microorganisms (Medlin et al. 1988, Lim et al. 1996, Marsh et al. 1998). Molecular techniques have recently provided new insights into marine protist diversity within pico- and nanoplankton. For example, $18 \mathrm{~S}$ ribosomal DNA libraries revealed an astonishing diversity among picoeukaryotes with novel phylogenetic lineages of yet uncultured organisms (Díez et al. 2001b, López-García et al. 2001, Moon-van der Staay et al. 2001). Fluorescent in situ hybridization (FISH) with eukaryote-specific probes has been used for quantitative studies of heterotrophic marine protists (Caron et al. 1999, Lim et al. 1999, Massana et al. 2002). Similar to bacteria, the eukaryotic diversity of complex communities has been visualized by PCR-based DNA fingerprinting techniques such as denaturing gradient gel electrophoresis (DGGE) (van Hannen et al. 1998, Díez et al. 2001a, Rasmussen et al. 2001, Gast et al. 2004) and restriction fragment length polymorphism (Lim et al. 2001).

Van Hannen et al. (1998) developed and used eukaryote-specific primers to analyze the diversity of protozoa in controlled culture experiments. The primers amplified a $210 \mathrm{bp}$ 18S rRNA gene fragment that could be separated by DGGE. This technique utilizes sequence dissimilarities in amplified DNA fragments of identical length and separates them on the basis of their differing mobility in an increasing denaturing gradient (Muyzer et al. 1993). It is assumed that the PCR-DGGE method reveals the dominating species or operational taxonomic units (OTUs) within the target group (e.g. species with cell numbers $>1 \%$ of total cell counts, Casamayor et al. 2000, review in Schäfer \& Muyzer 2001). Van Hannen et al. (1998) showed that the sequencing of gel bands made identification possible at the phylum level. Díez et al. (2001a) used another set of eukaryote-specific primers that yielded a 550 bp 18S rRNA gene fragment, and included pre-filtration of the samples to study diversity of picoeukaryotes in natural marine communities. Díez et al. (2001a) concluded in accordance with van Hannen et al. (1998) that DGGE was a profitable method for identification of eukaryotic diversity.

Nanoflagellate protists constitute a paraphyletic group of eukaryotes (Patterson 1999) and thus cannot, as one group, be separated from other eukaryotes on the basis of the 18S rDNA. One promising way to improve the resolution of the PCR-DGGE method for the analysis of protist communities is to develop groupspecific primers (Rasmussen et al. 2001, Gast et al. 2004). Primers specific for particular protist groups would allow selective amplification and analysis of relevant protists in natural systems.

Chrysophytes or golden-brown algae, including the closely related classes Chrysophyceae and Synurophyceae (Andersen \& Preisig 2002), are a diverse group of flagellates occurring in both fresh and marine waters. The group is classified within the heterokonts (also named stramenopiles by Patterson 1999) in the kingdom Chromista (Cavalier-Smith 1998). Species classified within Synurophyceae are mainly phototrophic, while the vast majority of the Chrysophyceae are mixotrophic and heterotrophic species (Holen \& Boraas 1995, Andersen \& Preisig 2002, Preisig \& Andersen 2002). The latter group supplements or replaces photosynthetic growth by ingesting bacteria or dissolved organic matter. Chrysomonads (Chrysophyceae) are a particularly important component of heterotrophic nanoflagellates (HNF) in planktonic systems where they, together with other heterokont taxa (e.g. bicosoecids), constitute 20 to $50 \%$ of HNF biomass (Boenigk \& Arndt 2002). Several genera of this group (e.g. Spumella, Ochromonas, Poterioochromonas) cannot be distinguished at the species level using a light microscope due to their lack of morphological features (Arndt et al. 2000). It is therefore of great importance to develop alternative methods for identification of diversity and population dynamics of chrysophytes in natural waters. The aim of this study was to develop and optimize chrysophyte-specific primers that could be utilized in DGGE. We began by using primers which were initially developed to distinguish different species within the genus Spumella (Bruchmüller 1998) and examined their applicability to amplify chrysophytes. These primers were then modified in order to match most of the currently known chrysophyte sequences, and the DGGE protocol was optimized for the analysis of chrysophyte diversity from natural water samples.

\section{MATERIALS AND METHODS}

Primer design. The primers designed for the genus Spumella were based on an alignment of 28 sequences of the 18S rRNA gene in chrysophytes and a wide range of eukaryotes (Bruchmüller 1998). In principle, the reverse primer was designed to be unique to the genus Spumella, while the forward primer targeted a wider range of eukaryotes. The specificity of these primers was tested again in January 2005, using all available sequences of chrysophytes in GenBank. The BLAST programme at the National Centre for Biotech- 
nology Information (NCBI), Washington, DC, USA (Altshul et al. 1997), and the ARB software version 04.06.28 (www.arb-home.de/) were used (Wolfgang et al. 2004). The primers amplify the highly variable V4 region of the $18 \mathrm{~S}$ gene. A GC rich sequence (GCclamp, see Table 1) was attached to the $5^{\prime}$ end of the forward primer in order to improve the performance of the DGGE (Sheffield et al. 1989).

Cell sampling and DNA extraction. Cultures were provided by the Culture Collection of Algae and Protozoa (CCAP) in the UK, the culture collection of algae (Sammlung von Algenkulturen Göttingen: SAG) at the University of Göttingen, Germany, and our own isolates at the Max Planck Institute for Limnology (MPIL) in Plön, Germany. All cultures with their taxonomic affiliations are listed in Table 2 . The cultures were grown in the supplied media and the cell condition was examined using a light microscope at $200 \times$ magnification. The cultures were harvested when the cell concentration was at least 1000 cells ml ${ }^{-1}$. For DNA extraction, 1.5 to $2 \mathrm{ml}$ of the cultures were concentrated through centrifugation at $10000 \mathrm{rpm}(9300 \times g)$ in an Eppendorf 5410 centrifuge and suspended in $150 \mu \mathrm{l}$ Milli-Q or Tris-EDTA (10 mM Tris-HCl; 1 mM EDTA; $\mathrm{pH}$ 8) buffer. In order to lyse the cells, they were frozen in liquid nitrogen and heated at $95^{\circ} \mathrm{C}$ for $20 \mathrm{~min}$. The lysate was centrifuged at maximum speed for $1 \mathrm{~min}$ and the supernatant was used in the PCR reaction.

Field samples from the low-productive northern Baltic Sea were collected from 0 to $20 \mathrm{~m}$ depth using a plastic hose ( $2.5 \mathrm{~cm}$ diameter). The hose was closed at the top and the entire water volume was collected. Offshore samples were collected in early July 2000 from 2 stations in the Bothnian Bay (BB1: 64 $14^{\circ} \mathrm{N}, 22^{\circ} 21^{\prime} \mathrm{E}$; $\mathrm{BB} 2: 64^{\circ} 42^{\prime} \mathrm{N}, 22^{\circ} 04^{\prime} \mathrm{E}$ ) and from 2 stations in the Bothnian Sea (BS1: $62^{\circ} 39^{\prime} \mathrm{N}, 18^{\circ} 57^{\prime} \mathrm{E}_{\text {; }} \mathrm{BS} 2: 62^{\circ} 05^{\prime} \mathrm{N}$, $18^{\circ} 32^{\prime}$ E). The samples were pre-filtered with a $90 \mu \mathrm{m}$ nylon filter and separated into different size fractions with 10 and $2 \mu \mathrm{m}$ pore size polycarbonate filters (Poretics $^{\circledR}$, Osmonics). Cells were collected by filtration onto $47 \mathrm{~mm}$ diameter $(0.6 \mu \mathrm{m}$ pore size) polycarbonate filters (Poretics ${ }^{\circledast}$, Osmonics). A water volume of 100 to $150 \mathrm{ml}$ was filtered depending on the amount of particles in the water. A maximum pressure of $50 \mathrm{~mm} \mathrm{Hg}$ was used in all filtrations. The filters were immediately frozen at $-70^{\circ} \mathrm{C}$ and stored for DNA extraction. DNA extraction methods were identical to those used for the cultures. The filters were submerged in Milli-Q water and heated at $95^{\circ} \mathrm{C}$.

Water samples from Schöhsee, a mesotrophic lake in northern Germany, were collected at $2 \mathrm{~m}$ depth 4 times during 2000 and 2001. For the extraction of DNA, 100 to $500 \mathrm{ml}$ were filtered onto $47 \mathrm{~mm}$ diameter $(0.2 \mu \mathrm{m}$ pore size) Durapore filters (Millipore) and stored in Petri dishes at $-80^{\circ} \mathrm{C}$ until DNA extraction. Extraction of DNA followed the protocol used for DNA extraction of bacterioplankton (Massana et al. 1997), which includes the addition of lysozyme, sodium dodecyl sulfate and Proteinase $\mathrm{K}$, followed by extraction with phenolchloroform-isoamyl alcohol (25:24:1, pH 8) and chloroform-isoamyl alcohol (24:1) and subsequent concentration and rinsing steps.

The concentration of DNA in the different extractions was measured spectrophotometrically in an Eppendorf BioPhotometer. Extracts from the cultures and the Baltic Sea samples had DNA concentrations of about $10 \mathrm{ng} \mathrm{hl}^{-1}$. Schöhsee samples contained on average $200 \mathrm{ng}$ of DNA $\mathrm{\mu l}^{-1}$.

PCR-DGGE. Amplifications of the 18S rDNA gene fragments in cultures and field samples were performed using the forward primers EukC1-F or EukC2$\mathrm{F}$ and the reverse Chryso-R primer (see Table 1). The PCR mixtures $(50 \mu \mathrm{l})$ contained on average $50 \mathrm{ng}$ of template DNA ( 400 ng for the Schöhsee samples), $1 \mu \mathrm{M}$ of each primer, $200 \mu \mathrm{M}$ of each deoxynucleoside triphosphate, $1.25 \mathrm{U}$ Taq DNA polymerase, and a PCR buffer containing $1.5 \mathrm{mM} \mathrm{Mg}^{2+}$ supplied with the polymerase (Roche).

The PCR programme consisted of 1 denaturation step at $94^{\circ} \mathrm{C}$ for 2 to $4 \mathrm{~min}$, followed by 30 (occasionally 35) cycles of denaturation at $94^{\circ} \mathrm{C}$ for $30 \mathrm{~s}$, annealing at 52 to $53^{\circ} \mathrm{C}$ for $30 \mathrm{~s}$, and extension at $72^{\circ} \mathrm{C}$ for $1 \mathrm{~min}$. The last cycle was followed by a final extension step at $72^{\circ} \mathrm{C}$ for $6 \mathrm{~min}$. The annealing temperature was empirically optimized around the melting temperature of the primers. The PCR products were confirmed in a $1.2 \%$ agarose gel electrophoresis. To verify that the DNA extraction had succeeded and to compare the performance of the chrysophyte-specific primers with other primer pairs, we also amplified the 18S rDNA from the 31 obtained cultures with eukaryote-specific primers (Euk1A and Euk516r-GC) according to Díez et al. 2001a (see Table 2). A dilution series of template DNA of Ochromonas sp. (Strain OE-1) was applied in PCR reactions to test the sensitivity of the different primer pairs. The original DNA extraction from approximately 20000 cells was diluted in 5 steps up to 200 times corresponding to about 100 cells.

DGGE was performed using both the Dcode Universal Mutation Detection System (Bio-Rad) and the DGGE-2001 System (CBS Scientific). Time travel experiments were performed, in which amplified DNA from cultures was applied on $1 \mathrm{~mm}$ thick $7.5 \%$ (wt/vol) polyacrylamide gels (ratio of acrylamide to bisacrylamide, 37.5:1). Several denaturation gradients between 20 and $60 \% \quad(100 \%$ denaturing agent was defined as $7 \mathrm{M}$ urea and $40 \%$ (wt/vol) deionized formamide) were used depending on samples and DGGE system. The optimal gradient was 40 to $60 \%$ denaturant and the optimal electrophoresis condition was 
$80 \mathrm{~V}$ for $16 \mathrm{~h}$. During electrophoresis the gels were submerged in $1 \mathrm{x}$ TAE buffer at 60 to $61^{\circ} \mathrm{C}$. The gels were stained for 30 min with SybrGreenI or SybrGold (Molecular Probes) diluted in 1x TAE buffer, and visualized in a STORM scanner (Molecular Dynamics gel scanner) or in a CCD-camera based gel documentation system (Geldoc 1000, BioRad).

DGGE bands from the field samples were cut out and sequenced to obtain their species affiliation. Small pieces of the bands were excised with a sterile pipette tip, suspended in Milli-Q water and stored at $4^{\circ} \mathrm{C}$ overnight. A total of $5 \mu \mathrm{l}$ of the supernatant was used for PCR reamplification under the same conditions as described above. The purity of the excised bands was verified on a second DGGE gel and then sequenced according to the manufacturer's recommendation with the DYEnamic ET terminator kit (Amersham Biosciences) and an ABI PRISM model 377 automated sequencer. The Chryso-R primer was used in the sequencing reaction. The resulting sequences were tested for possible chimeras by CHIMERA_CHECK version 2.7 at the Ribosomal Data Project (Cole et al. 2003).

\section{RESULTS}

\section{Primer specificity}

The primer pair EukC1-F and Chryso-R (Table 1), which was originally used to separate Spumella species (Bruchmüller 1998), amplifies a 218 base pair fragment of the nuclear-encoded 18S rRNA gene of the chrysophytes. In a search using the program BLAST (Altschul et al. 1997), a total of 73 classified or unclassified species of chrysophytes perfectly matched the Chryso-R reverse primer (e.g. Mallomonas spp., Ochromonas spp., Paraphysomonas spp., Poterioochromonas spp., Spumella spp., Synura spp.). Considering that 89 partial or total 18S rRNA gene sequences of chrysophyte taxa were in the NCBI GenBank (January 2005), $18 \%$ of the chrysophyte taxa were missed by the reverse primer. When one nucleotide mismatch was allowed another 8 sequences belonging to the chrysophyte taxa matched the Chryso-R primer (Chrysochaete britannica, AF123284; Dinobryon sertularia, AF123289; D. sociale var. americana, AF123291; Epipyxis pulchra, AF123298; Mallomonas caudata, U73228; M. matvienkoae, U73227; Oikomonas mutabilis, U42454; 'Spumella-like' flagellate JBC27, AY651093). In this case, $91 \%$ of presently known chrysophytes were matched. A few species, e.g. Antarctosaccion applanatum (AJ295822), Chlamydomyxa labyrinthuloides (AJ130893), Chromulina nebulosa (AF123285), Cyclonexis annularis (AF123292) and Paraphysomonas vestita (AF109325), had 2 or more bases different from the primer. The reverse primer did not miss any particular chrysophyte group. The results from an ARB analysis with 45 nearly complete chrysophyte $18 \mathrm{~S}$ sequences were consistent with the analysis by BLAST and the reverse primer matched exclusively the chrysophyte branch. Searching for an optimal primer without mismatches to any chrysophyte sequences with the probe design option in ARB did not result in a primer with higher coverage.

The EukC1-F primer perfectly matched a wide range of arthropods, flatworms and fungi, but only a few alveolates (16 species), annelids (10 species), chlorophytes (1 species) and molluscs (3 species). No cryptophytes or haptophytes matched the primer. The EukC1-F primer did, however, have 1 mismatch with about $30 \%$ of the chrysophytes, including members of the genera Chrysamoeba, Mallomonas and Synura. The primer perfectly matched members of Paraphysomonadaceae and Ochromonadales (clade $\mathrm{C}$ and clade F in Andersen et al. 1999). To include all chrysophytes, the second base from the $3^{\prime}$-end of the primer was set to a mixed base R (A or $G$, Table 1) in the EukC2-F forward primer. This primer with 1 degeneracy added included a wider range of organisms than the EukC1-F primer. The EukC2-F primer perfectly matched a range of different eukaryotes including alveolates, arthropods, annelids, chordates, flatworms, fungi, molluscs and members of Viridieplantae (e.g. chlorophytes). The primer did not match any haptophytes. All or most heterokonts and a few members of

Table 1. Oligonucleotide sequences tested in the study

\begin{tabular}{|c|c|c|c|}
\hline Primer & Sequence $5^{\prime}$ to $3^{\prime}$ & Specificity & Target site $^{\mathrm{a}}$ \\
\hline EukC1-F & bAAAGCTCGTAGTTGAA & Narrow eukaryotic & $613-628$ \\
\hline EukC2-F & bैAAAGCTCGTAGTTGRA ${ }^{\mathrm{c}}$ & Wide eukaryotic & $613-628$ \\
\hline Chryso-R & CCAACAAAATAGACCAAGG & Chrysophytes & $831-813$ \\
\hline \multicolumn{4}{|c|}{$\begin{array}{l}\text { a Numbers refers to the position in Poterioochromonas malhamensis 18S rRNA gene; accession no. AB023070 in the National } \\
\text { Centre for Biotechnology Information GenBank } \\
\text { b'The GC clamp used on the forward primer: 5'-CGCCCGCCCGCCCGTGCCGCCCCCGCCAG-3' } \\
\text { c IUPAC-IUB symbol: R = A or G }\end{array}$} \\
\hline
\end{tabular}


cryptophytes (4 species), euglenozoans (9 species) and rhodophytes (3 species) perfectly matched the degenerated primer. The EukC2-F primer matched all chrysophyte species except Chromulina nebulosa. Hence in theory the EukC2-F-Chryso-R primer pair perfectly matched $82 \%$ of known sequences of chrysophytes. The EukC1-F- Chryso-R primer pair matched $\sim 60 \%$ of known chrysophytes, but perfectly covered typically biflagellate taxa, e.g. Ochromonadales and Paraphysomonadaceae (Andersen et al. 1999). From the recently published sequences of 28 'Spumella-like' flagellates (Boenigk et al. 2005), 24 were matched by the former and 23 by the latter primer pair. Only isolates related to Oikomonas sp., Cyclonexis annularis and Ochromonas tuberculata were not targeted by the primers. Both primer pairs also matched 21 uncultured eukaryotic sequences obtained from marine and freshwater clone libraries (Díez et al. 2001b, Amaral Zettler et al. 2002, Edgcomb et al. 2002, Stoeck \& Epstein 2003). Three species of oomycetes (Leptolegnia caudata, AJ238659; L. chapmanii, AJ238660; and Aphanomyces sp., AF396683), 1 ciliate (Glauconema trihymene, AY169274), 1 diatom clone (clone CCW27, AY180017) and 1 dinoflagellate (Oxyrrhis marina, AY566418) were incorrectly matched by the primers.

We further tested the 2 primer pairs in PCR reactions with a wide range of cultures. Both freshwater and marine species belonging to Chrysophyceae or Synurophyceae and related groups were included in the analysis (Table 2). The general eukaryote primers

Table 2. Cultured strains used in the PCR test. Culture collections used were SAG: Sammlung von Algenkulturen (culture collection of algae) Göttingen; MPIL: Max Planck Institute for Limnology; CCAP: Culture Collection of Algae and Protozoa. $\mathrm{x}$ : sequences found in the National Centre for Biotechnology Information GenBank; accession number given if the strain was sequenced. Positive or negative PCR amplification with eukaryotic primers Euk1A-Euk516r-GC (Sogin \& Gunderson 1987, Amann et al. 1990) and chrysophyte primers (Chrys1: EukC1-F-Chryso-R; Chrys2: EukC2-F-Chryso-R) are noted

\begin{tabular}{|c|c|c|c|c|c|c|c|}
\hline $\begin{array}{l}\text { Taxonomic } \\
\text { affinity }\end{array}$ & Species & Strain & Collection & In GenBank & $\begin{array}{l}\text { PCR } \\
\text { Euk }\end{array}$ & $\begin{array}{c}\text { PCR } \\
\text { Chrys1 }\end{array}$ & $\begin{array}{c}\text { PCR } \\
\text { Chrys2 }\end{array}$ \\
\hline Bicosoecida & Cafeteria roenbergensis Fenchel \& Patterson & $\mathrm{CR}$ & MPIL & $\mathrm{x}$ & + & - & - \\
\hline Bicosoecida & Psudobodo tremulans Griessmann & PT & MPIL & $\mathrm{x}$ & + & - & - \\
\hline Chrysophyceae & Chromulina chionophila Stein & $909 / 9$ & CCAP & - & + & + & + \\
\hline Chrysophyceae & C. ochromonoides auct. & $909 / 1$ & CCAP & - & + & + & + \\
\hline Chrysophyceae & Chromulina sp. & 17.97 & SAG & - & + & + & + \\
\hline Chrysophyceae & Dinobryon sertularia Ehrenberg & $917 / 2$ & CCAP & $\mathrm{x}$ & + & + & + \\
\hline Chrysophyceae & D. divergens Imhof & $917 / 1$ & CCAP & - & + & + & + \\
\hline Chrysophyceae & Ochromonas danica Pringsheim & $933-7$ & SAG & $\mathrm{x}$ & + & + & + \\
\hline Chrysophyceae & Ochromonas sp. & $933-10$ & SAG & - & + & + & + \\
\hline Chrysophyceae & Ochromonas sp. & OE-1 & MPIL & - & + & + & + \\
\hline Chrysophyceae & Ochromonas sp. & OS-3 & MPIL & - & + & + & + \\
\hline Chrysophyceae & O. tuberculata Hibberd & $933 / 27$ & CCAP & $\mathrm{x}$ & + & + & + \\
\hline Chrysophyceae & O. villosa Clarke \& Pennick & $933 / 25$ & CCAP & - & + & + & + \\
\hline Chrysophyceae & Paraphysomonas vestita Stokes & PS-2 & MPIL & $\mathrm{x}$ & + & + & + \\
\hline Chrysophyceae & $P$. vestita Stokes & $935 / 14$ & CCAP & $\mathrm{x}$ & + & - & - \\
\hline Chrysophyceae & Poterioochromonas malhamensis (Pringsheim) Peterfi & $933-1 \mathrm{C}$ & SAG & $\mathrm{x}$ & + & + & + \\
\hline Chrysophyceae & P. malhamensis & $933-1 d$ & SAG & $\mathrm{x}$ & + & + & + \\
\hline Chrysophyceae & P. malhamensis & $933-8$ & SAG & $\mathrm{x}$ & + & + & + \\
\hline Chrysophyceae & P. malhamensis & $933-9$ & SAG & $\mathrm{x}$ & + & + & + \\
\hline Chrysophyceae & P. malhamensis & $933-1 \mathrm{a}$ & SAG & $\mathrm{x}$ & + & + & + \\
\hline Chrysophyceae & Spumella sp. & $27-\mathrm{A}$ & MPIL & - & + & + & + \\
\hline Dictyochophyceae & Pseudopedinella elastica Skuja & 43.88 & SAG & $\mathrm{x}$ & + & - & - \\
\hline Dictyochophyceae & Rhizochromulina marina Hibberd \& Chretien.-Dinet & $950 / 1$ & CCAP & $\mathrm{x}$ & + & - & - \\
\hline Eustigmatophyceae & Nannochloropsis gaditana Moro et Andreoli & 2.99 & SAG & AF133819 & + & - & - \\
\hline Prymnesiophyceae & Pleurochrysis carterae (Braarud \& Fagerl.) Christensen & $961 / 8$ & CCAP & $\mathrm{x}$ & + & - & - \\
\hline Synurophyceae & Mallomonas tonsurata Teiling em. Krieger & 28.92 & SAG & - & + & + & + \\
\hline Synurophyceae & M. transsylvanica Peterfi et Momeu & 18.92 & SAG & - & + & + & + \\
\hline Synurophyceae & M. akrokomos Ruttner & 54.88 & SAG & $\mathrm{x}$ & + & - & + \\
\hline Synurophyceae & Synura echinulata Korshikov & 15.92 & SAG & - & + & + & + \\
\hline Synurophyceae & S. petersenii Korshikov & $950 / 1$ & SAG & $\mathrm{x}$ & + & - & + \\
\hline Synurophyceae & S. curtispina (Petersen et Hansen) Asmund & 29.92 & SAG & - & + & + & + \\
\hline Mixture 1 & P. carterae + O. villosa & & & & + & + & + \\
\hline Mixture 2 & P. carterae $+S$. petersenii & & & & + & - & + \\
\hline Mixture 3 & P. carterae + N. gaditana & & & & + & - & - \\
\hline Mixture 4 & P. carterae + N. gaditana $+O$. villosa & & & & + & + & + \\
\hline Mixture 5 & P. carterae $+N$. gaditana $+S$. petersenii & & & & + & - & + \\
\hline
\end{tabular}



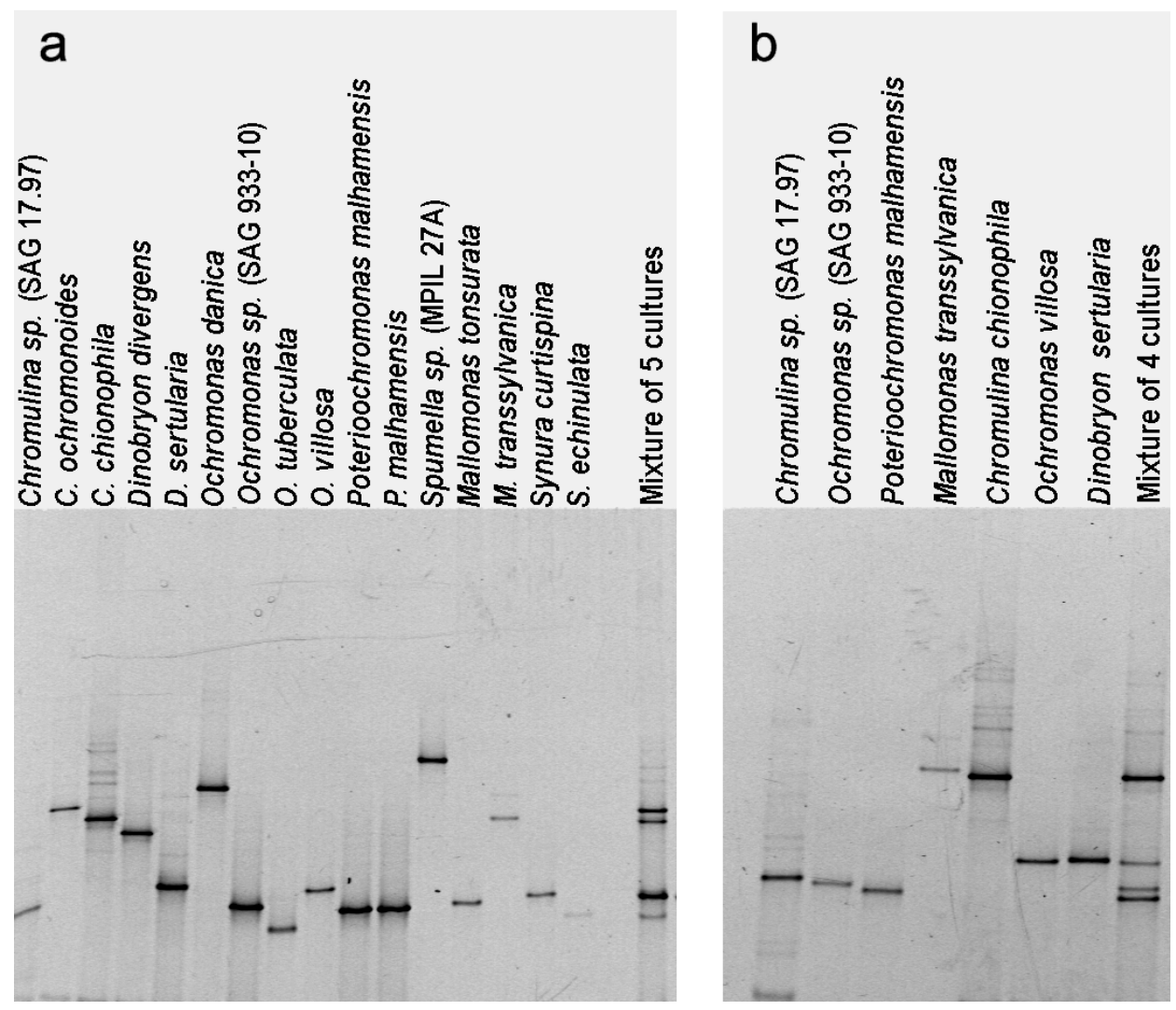

Fig. 1. (a) Denaturing gradient gel electrophoresis (DGGE) fingerprints of chrysophyte cultures in a denaturing gradient from 35 to $60 \%$. The mixture of PCR products contained Chromulina chionophila, Dinobryon divergens, Mallomonas transsylvanica, Ochromonas tuberculata and Poterioochromonas malhamensis. (b) Closely positioned cultures reapplied on a denaturing gradient of 40 to $60 \%$. The mixture of PCR products contained Chromulina sp., Poterioochromonas malhamensis, C. chionophila and Ochromonas villosa. PCR was done with the EukC1-F-Chryso-R primer pair in (a) and (b)

(Euk1A and Euk516r-GC) were used as a positive control. As expected this primer pair amplified all cultures. The EukC1-F-Chryso-R primer pair amplified all chrysophyte cultures except for Mallomonas akrokomos, Synura petersenii and 1 strain of Paraphysomonas vestita. The EukC2-F-Chryso-R primer pair also missed the $P$. vestita strain but amplified all other chrysophytes (Table 2). None of the non-chrysophyte species resulted in any PCR product. We also mixed the DNA from some chrysophyte cultures with nonchrysophyte ones to see if the primers could amplify target DNA in competition with non-target DNA (Mixtures 1 to 5, Table 2). The PCR amplification was always positive when the mixture contained matching chrysophyte DNA. The sensitivity test of all 3 primer pairs showed that they all amplified DNA from a 200 times diluted template, corresponding to about 100 cells (data not shown).

\section{DGGE analysis}

PCR products from cultures were analyzed by DGGE to reveal the potential of DGGE to separate the different organisms. The PCR products from the cultures were separated within a 35 to $60 \%$ denaturing gradi- ent and showed sharp single bands in the DGGE gel (Fig. 1a). The bands of some cultures, e.g. Chromulina sp., Ochromonas sp., Poteriochromas malhamensis and Mallomonas tonsurata, were positioned closely together in the gel (Fig. 1a). A randomly mixed sample of PCR products also showed that 2 bands (Mallomonas transsylvanica and Chromulina chionophila) occurred at the same position in the gel. In another gel with a steeper denaturing gradient (40 to $60 \%$ ) the cultures displayed an improved resolution (Fig. 1b). In the steeper gradient only 2 cultures Ochromonas villosa and Dinobryon sertularia were not properly separated. The PCR product from C. chionophila showed several bands on the DGGE gel. Probably there was some fragmented DNA, for example due to overloading the PCR reaction with template DNA. Intra-specific variation in the $18 \mathrm{~S}$ gene in the actual species could be another explanation.

DGGE patterns from the northern Baltic Sea revealed between 2 and 5 different sharp DGGE bands or OTUs with the EukC1-F and Chryso-R primers (Fig. 2a). The samples from Bothnian Bay had distinctly different band patterns to those of samples from the Bothnian Sea (Fig. 2a), while within the 2 basins the DGGE profiles were almost identical. The smallest size fraction $(<2 \mu \mathrm{m})$ showed no PCR product and con- 
Fig. 2. (a) DGGE fingerprints from seawater samples from 2 stations in the Bothnian Bay (BB1, BB2) and 2 stations in the Bothnian Sea (BS1, BS2), Baltic Sea, collected in July 2000. Different size fractions $(<2$, $<10$ and $<90 \mu \mathrm{m}$ ) of the samples are noted. Bands that were sequenced are indicated with arrows. DGGE was performed in a 40 to $60 \%$ denaturing gradient. PCR was done with the EukC1-F-Chryso-R primer pair. (b) PCR-DGGE fingerprints from the same Bothnian Sea samples, but the EukC2-Chryso-R primer pair was used for PCR. Sequences also

obtained in (a) are noted with *
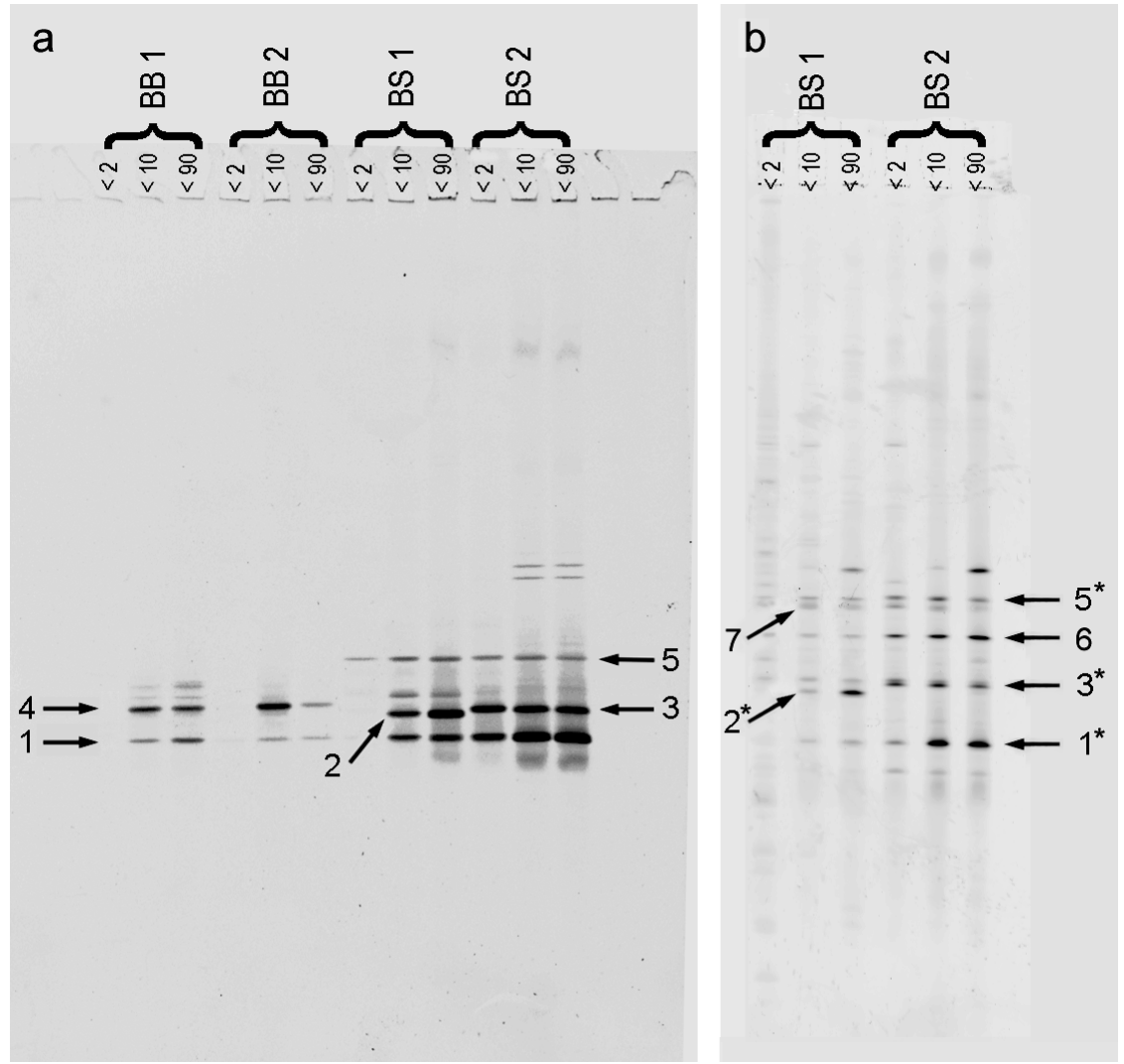

Table 3. Sequence similarities of excised denaturing gradient gel electrophoresis bands from field samples. Band numbers correspond to the arrows in Figs. 2 \& 3

\begin{tabular}{|c|c|c|c|c|c|c|}
\hline Band & $\begin{array}{l}\text { GenBank } \\
\text { accession }\end{array}$ & Closest alignment by BLAST & Taxonomic affinity & $\begin{array}{c}\text { Sequence } \\
\text { similarity (\%) }\end{array}$ & $\begin{array}{c}\text { Sequence } \\
\text { length }\end{array}$ & $\begin{array}{c}\text { Ambiguities } \\
(\% \mathrm{n})\end{array}$ \\
\hline \multicolumn{7}{|c|}{ Baltic Sea } \\
\hline $1,1^{*}$ & AY587572 & Paraphysomonas imperforata & Chrysophyceae & 95 & 202 & 1 \\
\hline $2,2^{*}$ & AY587573 & Uroglena americana & Chrysophyceae & 97 & 190 & 1.5 \\
\hline $3,3^{*}$ & AY587574 & Uncultured eukaryote C2_E045,_E001 & $\begin{array}{ll}1 \\
?\end{array}$ & 89 & 190 & 3 \\
\hline 4 & AY587575 & Paraphysomonas foraminifera & Chrysophyceae & 88 & 190 & 2.5 \\
\hline $5,5^{*}$ & AY587576 & Uncultured eukaryote E222 & $?$ & 91 & 190 & 0 \\
\hline 6 & - & Metanophrys similis, chimeric & $?$ & 93 & 120 & 1 \\
\hline 7 & - & Uncultured eukaryote C2_E018, chimeric & $?$ & 94 & 134 & 6 \\
\hline \multicolumn{7}{|c|}{ Schöhsee } \\
\hline 1 & AY587577 & Paraphysomonas foraminifera & Chrysophyceae & 86 & 190 & 0 \\
\hline 2 & AY587578 & Poterioochromonas malhamensis & Chrysophyceae & 98 & 200 & 0 \\
\hline 3 & AY587579 & Uroglena americana & Chrysophyceae & 98 & 200 & 0 \\
\hline 4 & AY587580 & Spumella sp. 15G (AJ236857) & Chrysophyceae & 93 & 195 & 1 \\
\hline 5 & AY587581 & Ochromonas danica & Chrysophyceae & 92 & 199 & 0 \\
\hline
\end{tabular}

sequently no DGGE bands, except for one of the samples from the Bothnian Sea. The samples from the Bothnian Sea were also amplified with the EukC2-F and Chryso-R primers and the subsequent DGGE revealed 5 to 7 different bands (Fig. 2b). In Schöhsee, a total of $\sim 14$ different bands were recognized by the DGGE analysis (Fig. 3).
The identity of the chrysophyte community in the Baltic Sea and Schöhsee was addressed by sequencing some dominant DGGE bands. Sequences from the Baltic Sea affiliated to the chrysophyte species Paraphysomonas imperforata, Paraphysomonas foraminifera and Uroglena americana (Table 3). Two of the sequences showed highest similarity to some uncul- 
tured eukaryotes (environmental clones C2_E001, C2_E045 and E222) that originated from clone libraries of the Guaymas Basin, California, USA (Edgcomb et al. 2002) and the Caribbean Sea, USA (Stoeck et al. 2003). Two of the sequences from the Baltic Sea were probably chimeric; consequently only a 120 or 134 bp fragment showed a significant match in BLAST (Bands 6 and 7, Table 3). Several of the sequences showed a relatively low sequence similarity value between 88 and $91 \%$. In the Schöhsee samples, the sequenced bands corresponded to the chrysophycean species $U$. americana, Poterioochromonas malhamensis, Ochromonas danica, P. foraminifera and Spumella sp. (Table 3).

We performed a phylogenetic analysis of the $18 \mathrm{~S}$ gene to evaluate the position of the uncultured eukaryotes that matched the obtained sequences from the field. Furthermore, a few sequences in GenBank that

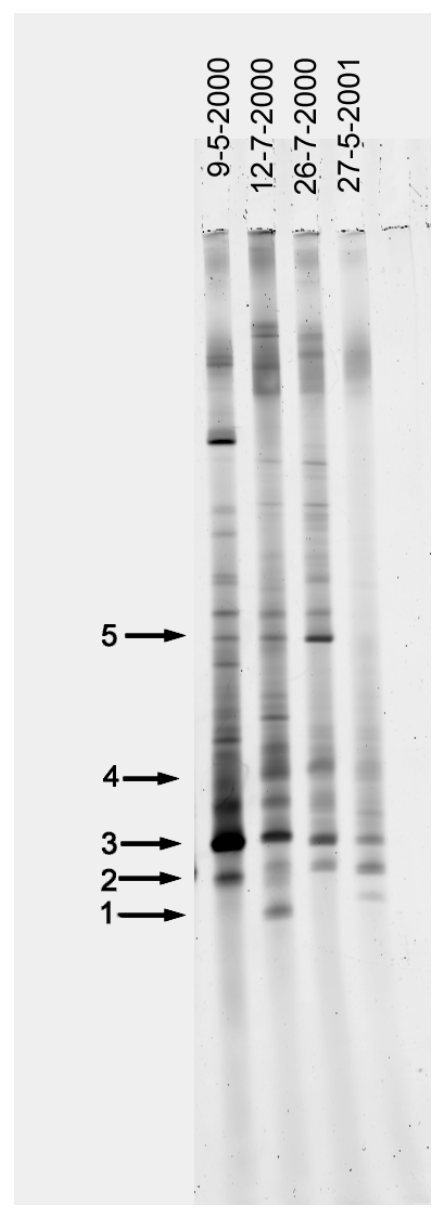

Fig. 3. DGGE fingerprints from Schöhsee at 4 different dates (9 May 2000, 12 July 2000, 26 July 2000 and 27 May 2001). Bands that were sequenced are indicated on the left-hand side of the gel. DGGE was performed in a 40 to $60 \%$ denaturing gradient. PCR was done with the EukC1-F-Chryso-R primer pair incorrectly matched the primers were included in the analysis, e.g. Glauconema trihymena, the diatom clone CCW27 and an uncultured stramenopile (clone LEMD106, AF372747). The analysis showed strong support for the chrysophyte group ( $j=100 \%$, Fig. 4). All of the obtained sequences from this study were found within the chrysophyte group. Similarly, the uncultured eukaryotes that matched the primers grouped within the chrysophytes. Hence, no nonchrysophyte sequences were retrieved from the DGGE analyses of the field samples.

\section{DISCUSSION}

The Chryso-R reverse primer had previously been used to distinguish species within the genus Spumella (Bruchmüller 1998). Our analysis, based on currently known sequences, revealed that the primer can be considered as specific for both class Chrysophyceae and class Synurophyceae, with the exceptions mentioned in the 'Results'. We could not find a primer that was able to sort out the whole chrysophyte group without mismatches. The reverse primer was used together with 2 different unspecific forward primers: EukC1-F, which mainly matched heterotrophic or mixotrophic chrysophytes; and EukC2-F, which matched all chrysophytes.

The primer pairs also seemed to detect some chrysophyte species with 1 nucleotide mismatch (shown for Dinobryon sertularia). The other 7 species with 1 nucleotide mismatch were not included in the PCR assay and should be tested in future studies. Sequences of Paraphysomonas vestita (Z28335 and AF109325) had 8 mismatches with the primers, but the PCR on cultures was positive for one strain (PS-2) and negative for another (935/14, Table 2). The reason for this could be either that there are intraspecific differences or that the positively amplified strain was wrongly identified as $P$. vestita. Considerable intraspecific sequence dissimilarity has been shown for $P$. vestita, and the sequence of $P$. vestita is also quite distinct from close relatives such as $P$. imperforata and $P$. foraminifera (Caron et al. 1999). In fact, the sequence of $P$. vestita (Z28335 or AF109325) showed an average of only $65 \%$ similarity to all of the chrysophyte sequences in GenBank.

The 18S rDNA sequence from a ciliate, a dinoflagellate and several eukaryotic clones matched the primers perfectly. However, the mismatch with the ciliate sequence (Glauconema trihymena, AY169274) could be ignored, since the phylogenetic analysis showed that it grouped within the chrysophytes (Fig. 4). In fact, the complete 18S rRNA gene sequence of the ciliate showed $97 \%$ similarity to Spumella elongata and $S$. 
danica, indicating that the ciliate culture was probably contaminated with flagellates. Similarly, the dinoflagellate sequence (Oxyrrhis marina, AY566418) showed high similarity to Spumella sequences. The sequences from several of the uncultured eukaryotic clones were also shown to belong to the chrysophytes (Fig. 4). As an example, the uncultured eukaryote clone C2_E045 (AY046830) had a 96\% sequence similarity to Spumella danica (AJ236861). Three 18S rRNA gene sequences from oomycetes (out of 292 oomycetes $18 \mathrm{~S}$ rDNA sequences in GenBank) were also recognized to match the primers. Oomycetes are a closely related group classified within the heterokonts (CavalierSmith 1998, Patterson 1999). PCR amplification of the theoretically matching species of oomycetes could not be verified, as no cultures were available to include in the PCR assay.

The EukC1-F-Chryso-R primer pair performed similarly to the EukC2-F-Chryso-R pair in the PCR test, except that the species Mallomonas akrokomos and Synura petersenii were not positively amplified with the EukC1-F-Chryso-R pair. The EukC1-F forward primer had 1 nucleotide mismatch with $M$. akrokomos and $S$. petersenii in the second base from the more

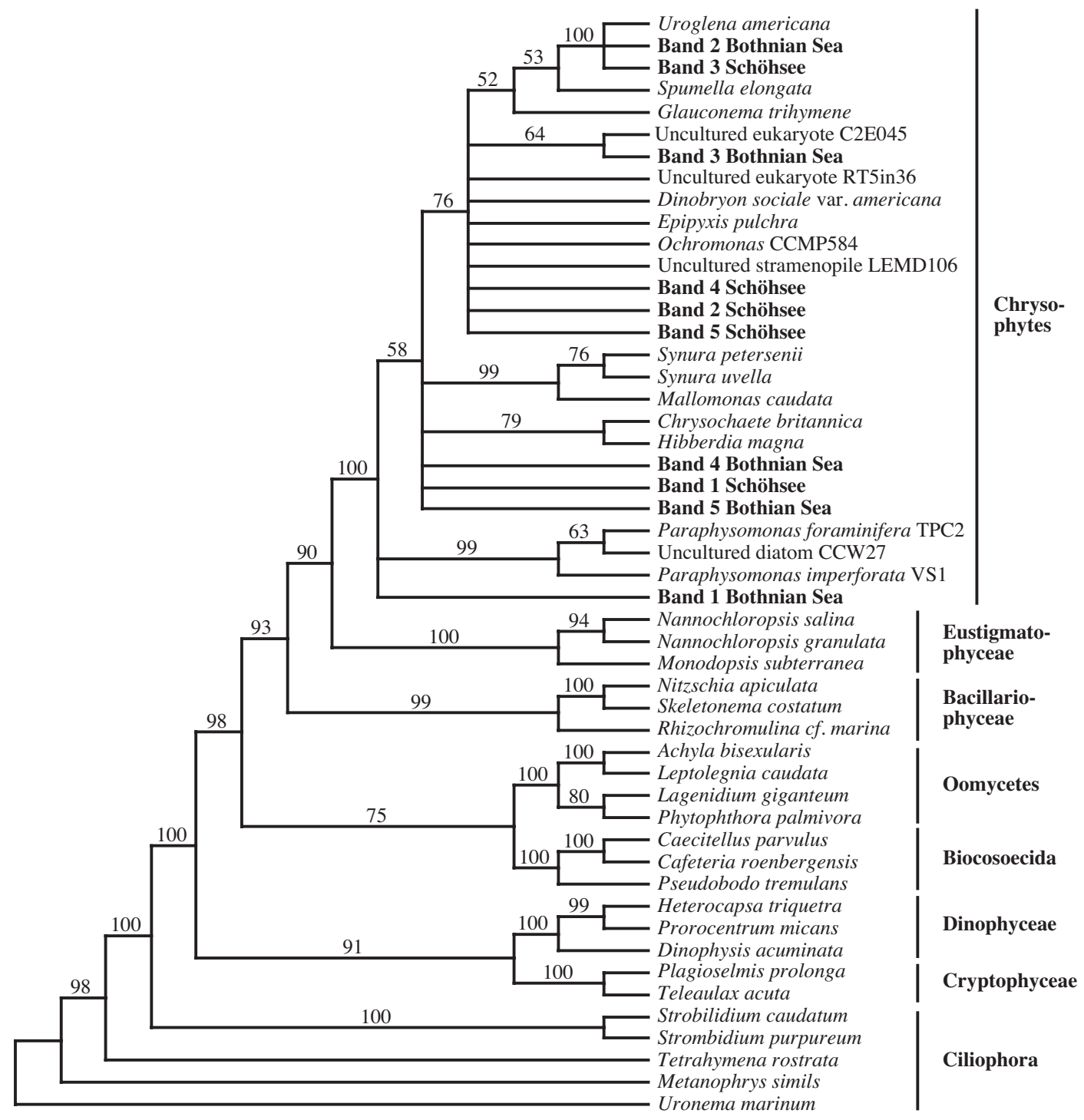

Fig. 4. Phylogenetic analysis of 50 sequences from a variety of both known and unknown eukaryote species. Sequences from this study are shown in bold. The tree is a $50 \%$ majority rule consensus tree resulting from parsimony jackknifing search (Farris et al. 1997) with PAUP* version 4.0 b10 for Macintosh (Swofford 2002; 1000 jackknifing replicates with $37 \%$ nominal deletion and JAC emulation; 5 random addition sequence replicates per jackknife replicate, full heuristic search, TBR branchswapping and MULTREES OFF). Uninformative characters were excluded from the analysis. The sequences were aligned using the Clustal W algorithm. Values above branches indicate jackknife values above $50 \%$ 
crucial 3' end of the primer. Altogether, 13 species of class Chrysophyceae and 14 species of class Synurophyceae, genera Mallomonas and Synura had the same mismatch. We conclude that the EukC1F-Chryso-R primer pair seems to be very useful for targeting widely occurring heterotrophic or mixotrophic groups of chrysophytes (e.g. the genera Ochromonas, Paraphysomonas, Poterioochromonas, Spumella, Uroglena), which are particularly important in freshwater plankton (Arndt et al. 2000). In contrast, the EukC2-F primer matched the whole target group. A disadvantage of this primer might be the wobbling position, since degenerated primers may form heteroduplex fragments or chimeras (Kowalchuk et al. 1997). Indeed, we recognized some likely chimeric sequences obtained from sharp DGGE bands of the field samples (Fig. 2b, Table 3). There are, however, studies showing that highly degenerated primers may perform well (Zeidner \& Béja 2004). The choice of primer pairs will depend on the specific questions raised in the study.

One aim was to optimize and use the primers for DGGE in order to analyze the natural diversity, distribution and dynamics of chrysophytes in pelagic systems. According to the DGGE analysis of pure cultures, most species were clearly separated in the applied denaturing gradient. However, some strains were stacked very close to each other in the gel, which may result in an incorrect estimation of the diversity in mixed samples. A single band from the same sample can contain more than one sequence. To further improve the separation, a steeper gradient of the denaturant or a double gradient of both denaturant and acrylamid concentrations might be used. The occurrence of strains at the same position also indicates the importance of sequencing the bands, since bands at the same position in adjacent lanes are not necessarily the same species. The occurrence of recombinant or chimeric sequences generated by the PCR reaction may complicate the DGGE analysis and give erroneous phylogenetic affiliations (Wang \& Wang 1997, Hugenholtz \& Huber 2003). By sequencing all bands and checking for chimeras, the correct species composition can be obtained. The biases inherent to all PCR based methods have to be recognized and kept to a minimum (von Wintzingerode et al. 1997). We occasionally used 35 amplification cycles in the PCR. However, the number of PCR cycles should be kept to a minimum, preferably between 25 and 30 , to minimize the occurrence of chimeras (Wang \& Wang 1997). Due to the detection limit of around $1 \%$ of total cell counts, it should also be recognized that the PCRDGGE method may not detect the total diversity, but it is very useful to reveal the dominating populations and changes in the community structure (Torsvik et al. 1998, Schäfer \& Muyzer 2001).
Relatively short sequence fragments $(\leq 500 \mathrm{bp})$ that can be analyzed in DGGE may set some limits for identification of organisms (e.g. van Hannen et al. 1998, Schäfer \& Muyzer 2001). This disadvantage is also valid for the chrysophyte primers, which amplify a 218 bp fragment. A longer fragment would give more phylogenetic information and a better resolution in the DGGE analysis. Nevertheless, the species detection ultimately depends on the sequence variability within the specific region of the DNA. Identification will at least be reduced from phylum level to family or genus level when utilizing phylum or class-specific primers. The correct identification of species is finally dependent on available sequence data in public gene banks. An advantage of using group-specific primers rather than wide-range primers is that there will be fewer bands to separate in the DGGE. This will improve the resolution and should minimize the occurrence of bands at the same position (Torsvik et al. 1998, Kisand \& Wikner 2003). The DGGE banding pattern of the cultures did not reflect the phylogenetic relationship, since closely related species did not travel to closer positions than more distantly related species. A weak connection between phylogenetic relationship and DGGE banding pattern has also been shown for prokaryotes (Kisand \& Wikner 2003).

The sequence identity of chrysophyte species that were dominant in the Baltic Sea and Lake Schöhsee did not reveal any unexpected species. The apparent ubiquitous genus Paraphysomonas (Finlay \& Clarke 1999) was identified in both the Baltic Sea and Schöhsee samples. Sequences corresponding to Uroglena americana were also found in both the Baltic Sea and Schöhsee. The higher number of OTUs from the Schöhsee samples may confirm the generally recognized importance of chrysophytes within the heterotrophic flagellates in freshwater plankton (Weisse 1997 , Auer \& Arndt 2001). However, it may also be the result of using a more thorough DNA extraction protocol compared to the one used for the Baltic Sea samples. The DNA concentration in the extractions from the Schöhsee samples was on average 20 times higher than in the extractions from the Baltic Sea. This was probably due to the difference in extraction protocol and filtration cut-off $(0.2 \mu \mathrm{m}$ for Schöhsee samples and $0.6 \mu \mathrm{m}$ for Baltic Sea samples). The Schöhsee samples probably contained a lot of bacterial DNA, which in contrast made it more difficult to selectively amplify the chrysophytes. We did not make a comparison between the different methods, but it can be concluded that the primers are working with different DNA extraction protocols.

Several of the sequences obtained from the field samples had a relatively low similarity (88 to $91 \%$ ) to known chrysophyte sequences in the NCBI GenBank 
(Table 3). The fragment that is amplified with the chrysophyte primers covers a variable region and the mean sequence similarity between all chrysophytes in the NCBI GenBank was $81 \%$ ('Sequence identity matrix' option in BioEdit 7.0.4). The similarity within genera such as Mallomonas, Paraphysomonas and Synura was $88 \%$. Hence, the sequences from the DGGE analysis are within the natural variability of the target group and sequence similarities higher than $88 \%$ should indicate the genera, while similarities $\geq 96$ to $97 \%$ probably indicate similar species. In general, the sequence similarities were higher in the Schöhsee samples than in the Baltic Sea samples, which might indicate that fewer species from the Baltic Sea are included in the GenBank. Hence, there is a need for more analyses of chrysophyte sequences to obtain correct identities.

In conclusion, the utilized primers and the PCRDGGE method were found to be adequate for detection and separation of the majority of chrysophytes in both cultures and natural water samples. Two different primer pairs were tested in this study, one that targeted mostly heterotrophic and mixotrophic chrysophytes and one that targeted all chrysophytes, also including the purely autotrophic forms (e.g. Synurophyceae). Amplified fragments from a mixed chrysophyte community can be analyzed using DGGE. The application of these primers with the PCR-DGGE approach should yield new insights into the diversity and population dynamics of this important group of nanoprotists in aquatic ecosystems. An advantage of this method is that closely related species among naked genera such as Ochromonas and Spumella can be separated on the ribosomal gene level.

Acknowledgements. We thank G. Jost and M. Labrenz for help with the ARB analysis, R. A. Andersen and E. Stacy for their help with primer specificity information, and M. Hanke for DNA samples from Schöhsee. T. Weisse and R. Massana provided valuable comments on an earlier draft of the manuscript B. Giles helped us to improve the language. This project was supported by Research Fellowship grants from the Federation of European Microbiological Societies and the Helge Ax:son Johanson foundation. We also express our thanks to Umeå Marine Science Centre for providing field samples and for financial support to Johnny Berglund and Agneta Andersson.

\section{LITERATURE CITED}

Altschul SF, Madden TL, Schäffer AA, Zhang J, Zhang Z, Miller W, Lipman DJ (1997) Gapped BLAST and PSIBLAST: a new generation of protein database search programs. Nucleic Acids Res 25:3389-3402

Amann RI, Madden TL, Schäffer AA, Zhang J, Zhang Z, Miller W, Lipman DJ (1990) Combination of 16S rRNAtargeted oligonucleotide probes with flow cytometry for analyzing mixed microbial populations. Appl Environ
Microbiol Rev 56:1919-1925

Amann RI, Ludwig W, Schleifer KH (1995) Phylogenetic identification and in situ detection of individual microbial cells without cultivation. Microbiol Rev 59:143-169

Amaral Zettler LA, Gomez F, Zettler E, Keenan BG, Amils R, Sogin ML (2002) Eukaryotic diversity in Spain's River of Fire-this ancient and hostile ecosystem hosts a surprising variety of microbial organisms. Nature 417: 137

Andersen RA, Preisig H (2002) Synurophyceae. In: Lee JJ, Leedale GF, Bradbury PC (eds) An illustrated guide to the Protozoa, 2nd edn, Vol 2. Society of Protozoologists, Lawrence, KS, p 759-775

Andersen RA, Van de Peer Y, Potter D, Sexton JP, Kawachi M, LaJeunesse T (1999) Phylogenetic analysis of the SSU rRNA from members of the Chrysophyceae. Protist 150:71-84

Arndt H, Dietrich D, Auer B, Cleven EJ, Gräfenhan T, Weitere M, Mylnikov A (2000) Functional diversity of heterotrophic flagellates in aquatic ecosystems. In: Leadbeater B, Green J (eds), The flagellates. Taylor \& Francis, London, p 240-268

Auer B, Arndt H (2001) Taxonomic composition and biomass of heterotrophic flagellates in relation to lake trophy and season. Freshw Biol 46:959-972

Boenigk J, Arndt H (2002) Bacterivory by heterotrophic flagellates: community structure and feeding strategies. Antonie Van Leeuwenhoek Int J Gen Mol Microbiol 81: $465-480$

Boenigk J, Pfandl K, Stadler P, Chatzinotas, A (2005) High diversity of the 'Spumella-like' flagellates: an investigation based on the SSU rRNA gene sequences of isolates from habitats located in six different geographic regions. Environ Microbiol 7:685-697 (doi:10.1111/j.1462-2920. 2005.00743.x)

Bruchmüller I (1998) Molekularbiologische Characterisierung und phylogenetische Einordnung heterotropher Nanoflagellaten und protomastider Ciliaten des Süsswassers. PhD thesis, Christian-Albrechts-Universität Kiel

Caron DA, Lim LE, Dennett MR, Gast RJ, Kosman C, DeLong EF (1999) Molecular phylogenetic analysis of the heterotrophic chrysophyte genus Paraphysomonas (Chrysophyceae), and the design of rRNA-targeted oligonucleotide probes for two species. J Phycol 35:824-837

Casamayor EO, Schäfer H, Baneras L, Pedrós-Alió C, Muyzer G (2000) Identification of and spatio-temporal differences between microbial assemblages from two neighboring sulfurous lakes: comparison by microscopy and denaturing gradient gel electrophoresis. Appl Environ Microbiol 66:499-508

Cavalier-Smith T (1998) A revised six-kingdom system of life. Biol Rev 73:203-266

Cole JR, Chai B, Marsh TL, Farris RJ and 7 others (2003) The Ribosomal Database Project (RDP-II): previewing a new autoaligner that allows regular updates and the new prokaryotic taxonomy. Nucleic Acids Res 31:442-443

Díez B, Pedrós-Alió C, Marsh TL, Massana R (2001a) Application of denaturing gradient gel electrophoresis (DGGE) to study the diversity of marine picoeukaryotic assemblages and comparison of DGGE with other molecular techniques. Appl Environ Microbiol 67:2942-2951

Díez B, Pedrós-Alió C, Massana R (2001b) Study of genetic diversity of eukaryotic picoplankton in different oceanic regions by small-subunit rRNA gene cloning and sequencing. Appl Environ Microbiol 67:2932-2941

Edgcomb VP, Kysela DT, Teske A, de Vera Gomez A, Sogin ML (2002) Benthic eukaryotic diversity in the Guaymas Basin hydrothermal vent environment. Proc Natl Acad Sci USA 99:7658-7662 
Farris JS, Albert VA, Källersjö M, Lipscomb D, Kluge AG (1997) Parsimony jackknifing outperforms neighborjoining. Cladistics 12:99-124

Finlay BJ, Clarke KJ (1999) Apparent global ubiquity of species in the protist genus Paraphysomonas. Protist 150: $419-430$

Gast RJ, Dennett MR, Caron DA (2004) Characterization of protistan assemblages in the Ross Sea, Antarctica by denaturing gradient gel electrophoresis. Appl Environ Microbiol 70:2028-2037

Holen D, Boraas M (1995) Mixotrophy in chrysophytes. In: Sandgren C, Smol J, Kristiansen J (eds) Chrysophyte algae; ecology, phylogeny and development. Cambridge University Press, Cambridge, p 119-140

Hugenholtz P, Huber T (2003) Chimeric 16S rDNA sequences of diverse origin are accumulating in the public databases. Int J Syst Evol Microbiol 53:289-293

Kisand V, Wikner J (2003) Limited resolution of 16S rDNA DGGE caused by melting properties and closely related DNA sequences. J Microbiol Methods 54:183-191

Kowalchuk GA, Stephen JR, De Boer W, Prosser JI, Embley TM, Woldendorp JW (1997) Analysis of ammoniaoxidizing bacteria of the beta subdivision of the class Proteobacteria in coastal sand dunes by denaturing gradient gel electrophoresis and sequencing of PCR-amplified 16S ribosomal DNA fragments. Appl Environ Microbiol 63:1489-1497

Lim EL, Caron DA, Delong EF (1996) Development and field application of a quantitative method for examining natural assemblages of protists with oligonucleotide probes. Appl Environ Microbiol 62:1416-1423

Lim EL, Dennett MR, Caron DA (1999) The ecology of Paraphysomonas imperforata based on studies employing oligonucleotide probe identification in coastal water samples and enrichment cultures. Limnol Oceanogr 44:37-51

Lim EL, Dennett MR, Caron DA (2001) Identification of heterotrophic nanoflagellates by restriction fragment length polymorphism analysis of small subunit ribosomal DNA. J Eukaryot Microbiol 48:247-257

López-García P, Rodriguez-Valera F, Pedros-Alio C, Moreira D (2001) Unexpected diversity of small eukaryotes in deep-sea Antarctic plankton. Nature 409:603-607

Marsh TL, Liu WT, Forney LJ, Cheng H (1998) Beginning a molecular analysis of the eukaryal community in activated sludge. Water Sci Technol 37:455-460

Massana R, Murray AE, Preston CM, Delong EF (1997) Vertical distribution and phylogenetic characterization of marine planktonic archaea in the Santa Barbara Channel. Appl Environ Microbiol 63:50-56

Massana R, Guillou L, Díez B, Pedrós-Alió C (2002) Unveiling the organisms behind novel eukaryotic ribosomal DNA sequences from the ocean. Appl Environ Microbiol 68: 4554-4558

Medlin L, Elwood HJ, Stickel S, Sogin ML (1988) The characterization of enzymatically amplified eukaryotic 16S-like rRNA-coding regions. Gene 71:491-500

Moon-van der Staay SY, De Wachter R, Vaulot D (2001) Oceanic 18S rDNA sequences from picoplankton reveal unsuspected eukaryotic diversity. Nature 409:607-610

Muyzer G, De Waal EC, Uitterlinden AG (1993) Profiling of complex microbial populations by denaturing gradient gel electrophoresis analysis of polymerase chain reaction

Editorial responsibility: David A. Caron,

Los Angeles, California, USA amplified genes coding for 16S rRNA. Appl Environ Microbiol 59:695-700

Patterson DJ (1999) The diversity of eukaryotes. Am Nat 154: 96-124

Preisig HR, Andersen RA (2002) Chrysophyceae. In: Lee JJ, Leedale GF, Bradbury PC (eds) An illustrated guide to the Protozoa, 2nd edn, Vol 2. Society of Protozoologists, Lawrence, KS, p 693-730

Rasmussen L, Ekelund F, Hansen L, Sorensen S, Johnsen K (2001) Group-specific PCR primers to amplify 24S alphasubunit rRNA genes from Kinetoplastida (Protozoa) used in denaturing gradient gel electrophoresis. Microb Ecol 42:109-115

Schäfer H, Muyzer G (2001) Denaturing gradient gel electrophoresis in marine microbial ecology. In: Paul J (ed) Methods in microbiology: marine microbiology, Vol 30. Academic Press, London, p 425-468

Sheffield DR, Cox DR, Lerman LS, Meyers RM (1989) Attachment of a 40 base pair $\mathrm{G}+\mathrm{C}$-rich sequence (GC-clamp) to genomic DNA by the polymerase chain reaction results in improved detection of single-base changes. Proc Natl Acad Sci USA 86:232-236

Sherr EB, Sherr BF (2002) Significance of predation by protists in aquatic microbial food webs. Antonie Van Leeuwenhoek Int J Gen Mol Microbiol 81:293-308

Sogin ML, Gunderson JH (1987) Structural diversity of eukaryotic small subunit ribosomal RNAs. Ann NY Acad Sci 503:125-139

Stoeck T, Epstein S (2003) Novel eukaryotic lineages inferred from small-subunit rRNA analyses of oxygen-depleted marine environments. Appl Environ Microbiol 69: $2657-2663$

Stoeck T, Taylor GT, Epstein SS (2003) Novel eukaryotes from the permanently anoxic Cariaco Basin (Caribbean Sea). Appl Environ Microbiol 69:5656-5663

Swofford DL (2002) PAUP* phylogenetic analysis using parsimony (*and other methods), version 4.0 b10. Sinauer Associates, Sunderland, MA

Torsvik V, Daae FL, Sandaa RA, Øverås L (1998) Novel techniques for analysing microbial diversity in natural and perturbed environments. J Biotechnol 64:53-62

van Hannen E, van Agterveld M, Gons HJ, Laanbroek H (1998) Revealing genetic diversity of eukaryotic microorganisms in aquatic environments by denaturing gradient gel electrophoresis. J Phycol 34:206-213

von Wintzingerode F, Gobel UB, Stackebrandt E (1997) Determination of microbial diversity in environmental samples:pitfalls of PCR-based rRNA analysis. FEMS Microbiol Rev 21:213-229

Wang GCY, Wang Y (1997) Frequency of formation of chimeric molecules is a consequence of PCR coamplification of 16S rRNA genes from mixed bacterial genomes. Appl Environ Microbiol 63:4645-4650

Weisse $\mathrm{T}$ (1997) Growth and production of heterotrophic nanoflagellates in a meso-eutrophic lake. J Plankton Res 19:703-722

Wolfgang L, Strunk O, Westram R, Richter L and 28 others (2004) ARB: a software environment for sequence data. Nucleic Acids Res 32:1363-1371

Zeidner G, Béja O (2004) The use of DGGE analyses to explore eastern Mediterranean and Red Sea marine picophytoplankton assemblages. Environ Microbiol 6:528-534

Submitted: August 18, 2004; Accepted: March 10, 2005

Proofs received from author(s): April 25, 2005 